\title{
Differentiation-inducing and anti-proliferative activities of lupeol on canine melanoma cells
}

\author{
Kikumi Ogihara', Yuko Naya', Yoshiharu Okamoto ${ }^{2}$ and Keishi Hata ${ }^{3 *}$
}

\begin{abstract}
Canine melanoma is the most common oral malignant tumor reported in the field of veterinary medicine. We found that lupeol, a lupine triterpene, inhibited mouse melanoma cell growth in vitro and in vivo by inducing cell differentiation. In the present study, we examined the differentiation-inducing activities of lupeol on 4 canine melanoma cells in vitro and in vivo.

The induction of canine melanoma cell differentiation by lupeol was confirmed by evaluating some differentiation markers such as tyrosinase with real-time RT-PCR. Furthermore, we transplanted canine melanoma cells into a severe combined immunodeficiency mouse, and studied the anti-progressive effects of lupeol on tumor tissue. The gene expression of microphthalmia-associated transcription factor, tyrosinase, and tyrosinase-related protein-2, which are markers of pigment cell differentiation, was induced in 4 canine oral malignant melanoma cells by lupeol, and the agent markedly inhibited tumor progression in canine melanoma-bearing mice.
\end{abstract}

Keywords: Lupeol; Canine melanoma; Differentiation-inducing activity; Cytostatic effect; Nonsurgical treatment

\section{Introduction}

Melanoma is the most aggressive form of skin cancer that is derived from activated or genetically altered epidermal melanocytes (Oliveria et al. 2001). Human malignant melanoma is a highly metastatic cancer that is markedly resistant to chemotherapy with dacarbazine or temozolomide. Canine melanoma is the most common oral malignant tumor reported in the field of veterinary medicine (Bergman, 2007). It was reported that treatment of carboplastin significantly affects dogs with malignant melanoma, and achieved a response rate at $28 \%$ (Rassnick et al. 2001).

Lupeol, a plant pentacyclic triterpene, was previously shown to have various biological activities, such as antiinflammatory (Fernández et al. 2001a,b), anti-cancer (Saleem 2009), and anti-metabolic syndrome (Sasaki et al. 2008; Hata et al. 2008; Itoh et al. 2009) activities. We previously demonstrated that lupeol inhibited mouse melanoma cell growth by inducing melanogenesis and suppressing the motility of cells (Hata et al. 2006). These findings revealed that lupeol induced the differentiation of melanoma

\footnotetext{
* Correspondence: hata@arif.pref.akita.jp

${ }^{3}$ Akita Research Institute of Food and Brewing, 4-26 Sanuki, Araya-machi, Akita 010-1623, Japan

Full list of author information is available at the end of the article
}

cells into mature melanocyte-like cells in vitro. In our recent study, we showed that lupeol suppressed tumor growth in melanoma-bearing mice by attenuating proliferating cell nuclear factor (PCNA) and Ki67, which are highly expressed in melanoma or other tumors (Nitta et al. 2013). However, the effects of lupeol on other melanoma such as canine melanoma remain unclear. In the present study, we examined the differentiation-inducing activities of lupeol on canine melanoma cells in vitro and its antimelanoma effects in vivo, prior to clinical trials on canine melanoma.

\section{Material and methods \\ Cell culture}

With prior written informed consents of animal owners, 4 melanoma samples were separately harvested after surgical procedures, and 4 canine oral malignant melanoma (cMEL) cell lines were established from these tumor samples. The three melanoma cell lines (cMEL-1, -3 , and -4) were maintained in Dulbecco's modified Eagle's medium, and cMEL-2 cells were maintained in RPMI-1640 medium, respectively, supplemented with $10 \%$ fetal calf serum, $100 \mu \mathrm{g} / \mathrm{ml}$ of streptomycin, and $100 \mathrm{U}$ of penicillin. 
Effect of lupeol on canine melanoma cell growth

Aliquots of $1 \mathrm{ml}$ of cMEL-1-4 cells $\left(1 \times 10^{4}\right.$ cells $)$ were incubated with various concentrations of lupeol (SigmaAldrich, INC.) for 4 days, and the number of viable cells was counted by trypan blue exclusion method. $\mathrm{IC}_{50}$ values, representing the concentration that inhibited melanoma cell growth by $50 \%$, were measured.

\section{RNA extraction and CDNA synthesis}

Canine melanoma cells $\left(2 \times 10^{4}\right.$ cells $)$ in $10 \mathrm{~cm}$-dishes $(10 \mathrm{ml})$ were incubated with or without lupeol for 2 days. Total RNA was isolated using the QuickGene RNA cultured cell kit S (FUJIFILM, Co.). Template cDNA synthesis was performed with $5 \mu \mathrm{g}$ of total RNA using the PrimeScript RT Reagent Kit (TAKARA BIO, INC.)

\section{Real-time RT-PCR}

In a fluorescent temperature cycler (Chromo4; Bio-Rad Laboratories, Inc.), $2.5 \%$ of each RT reaction solution was amplified in $25 \mu \mathrm{l}$ of $1 \times$ SYBR Premix Ex Taq (TAKARA $\mathrm{BIO}$, INC.) containing $0.2 \mu \mathrm{M}$ of each primer. Samples were incubated in the thermal cycler for an initial denaturation at $95^{\circ} \mathrm{C}$ for $10 \mathrm{~s}$, followed by 40 PCR cycles. Each cycle consisted of $95^{\circ} \mathrm{C}$ for $5 \mathrm{~s}$ and $60^{\circ} \mathrm{C}$ for $30 \mathrm{~s}$. The oligonucleotide primers used in the present study are indicated in Table 1. To confirm the amplification of specific transcripts, melting curve profiles (cooling the sample to $60^{\circ} \mathrm{C}$ and heating slowly to $95^{\circ} \mathrm{C}$ with the continuous measurement of fluorescence) were produced at the end of each PCR. The relative expression level of each mRNA was normalized by the amount of GAPDH mRNA.

Table 1 Oligonucleotide primers used in real-time RT-PCR

\begin{tabular}{ll}
\hline Target gene & Primer sequence (5'-3') \\
\hline GAPDH & S:-GCCAAGAGGGTCATCATCTC \\
MITF & A:-GGCCCGTCCACGGTCTTCT \\
& S:-GGGATTGATGGATCCTGCTTG \\
TYR & A:-GGCTGGACAGGAGTTGCTGA \\
& S:-TTGGCAGATTGTCTGTAGCC \\
TRP-2 & A:-AGGCATTGTGCATGCTGCTT \\
& S:-ACACAACACTGGCTGGGCCT \\
PCNA & A:-GAGATCTCTTTCCAGACACAAC \\
& A:-AGCTGAACTGGCTCATTCATCTCTA \\
Ki67 & S:-AATCTCTGCTTCGGGTCTCCA \\
& A:-ACTCCGGTTCAGACGACCAC \\
\hline
\end{tabular}

GAPDH Glyceraldehyde-3-phosphate dehydrogenase, MITF microphthalmiaassociated transcription factor, TYR tyrosinase, TRP-2 tyrosinase-related protein 2, PCNA proliferating cell nuclear factor, $S$ sense, $A$; antisense.

\section{Subcutaneously administration of lupeol to canine melanoma-bearing mice}

C.B-17/Icr-scid/scid Jc severe combined immunodeficiency (SCID) mouse were obtained from Crea Japan, INC.. A total of $1 \times 10^{7}$ cMEL-2 cells were subcutaneously injected into the back regions of SCID mice. Mice whose tumors grew to $10 \mathrm{~mm}$ in size were used in this study (day 0). Fifteen mice were randomized into 3 groups on day 0 ( $n=5 /$ group). Tumors were removed from 5 mice on day 0 and their weights were measured (day 0 group). Single injections of olive oil (0.1 ml, vehicle control group) or $0.5 \mathrm{mg}$ lupeol in $0.1 \mathrm{ml}$ olive oil (lupeol group) were subcutaneously administered around tumor tissue of each mouse at day 0 . The tumor tissues of each mouse were removed 10 days after the injections, and their weights were measured. The experimental plan of the study was approved by the Ethics Committee for Animal Experimentation of Azabu University.

\section{Statistical analysis}

Data are expressed as the mean \pm standard deviation (SD). The significance of differences was analyzed using the Student's t-test (Figures 1, 2, 3) and one-way ANOVA with Tukey's multiple comparison test (Figure 4). A value of $p<0.05$ was considered significant.

\section{Results and discussion}

We investigated whether lupeol induced the differentiation of canine oral malignant melanoma (cMEL) cells by evaluating some differentiation markers with real-time RT-PCR. Figure 1 shows the effects of $5 \mu \mathrm{M}$ lupeol on the gene expression of microphthalmia-associated transcription factor (MITF), tyrosinase (TYR), and tyrosinase-related protein-2 (TRP-2) in 4 canine melanoma cells. Lupeol up-regulated MITF genes 1.5-3.1-fold, TYR genes 1.8-5.7-fold, and TRP2 genes 1.9-3.9-fold, respectively, which indicated that the agent induced the differentiation of canine melanoma cells as well as mouse melanoma cells.

The proliferation of 4 canine melanoma cells was markedly suppressed by $10 \mu \mathrm{M}$ lupeol, and this agent exhibited particularly strong anti-proliferative effects on cMEL-1 and -2 cells (Figure 2). The $\mathrm{IC}_{50}$ values of lupeol against 4 melanoma cells were $5.6 \mu \mathrm{M}$ (cMEL-1), $2.3 \mu \mathrm{M}$ (cMEL-2), $15.7 \mu \mathrm{M}$ (cMEL-3), and $15.7 \mu \mathrm{M}$ (cMEL-4), respectively; however, even at each $\mathrm{IC}_{50}$, all melanoma cells did not detach and remained $>95 \%$ viable, suggesting that the inhibition of cell growth by lupeol can be attributed to its cytostatic (differentiationinducing), but not cytotoxic effects.

PCNA is a cell-cycle regulator expressed in the nucleus of proliferating cells. The degree of PCNA expression has been correlated with tumor progression and grade in some tumors (Zeng and Davis 2003; Hall et al. 1990; Malham et al. 2010). Ki67 is also a cell proliferation marker, and the expression of Ki67 in the numerous 

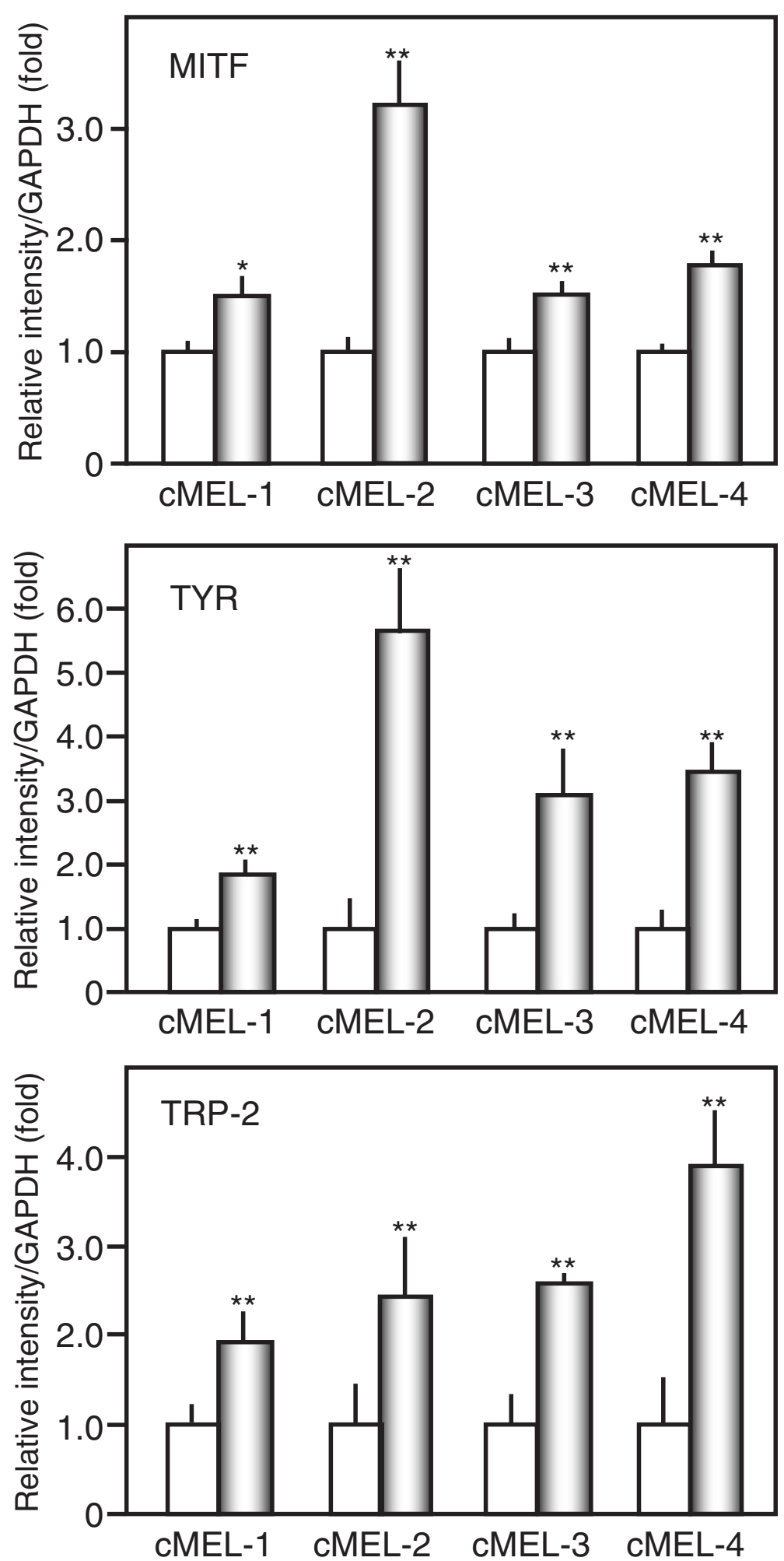

Figure 1 Up-regulation of melanoma cell differentiation markers by lupeol. Four canine melanoma cells $\left(2 \times 10^{5}\right.$ cells) were treated without (white bar) or with $5 \mu \mathrm{M}$ lupeol (gray bar) for $48 \mathrm{~h}$, and the gene expression of MITF, TYR, and TRP-2 was measured by real-time RT-PCR. ${ }^{*} p<0.05,{ }^{* *} p<0.01$ vs untreated cells $(n=3)$. 


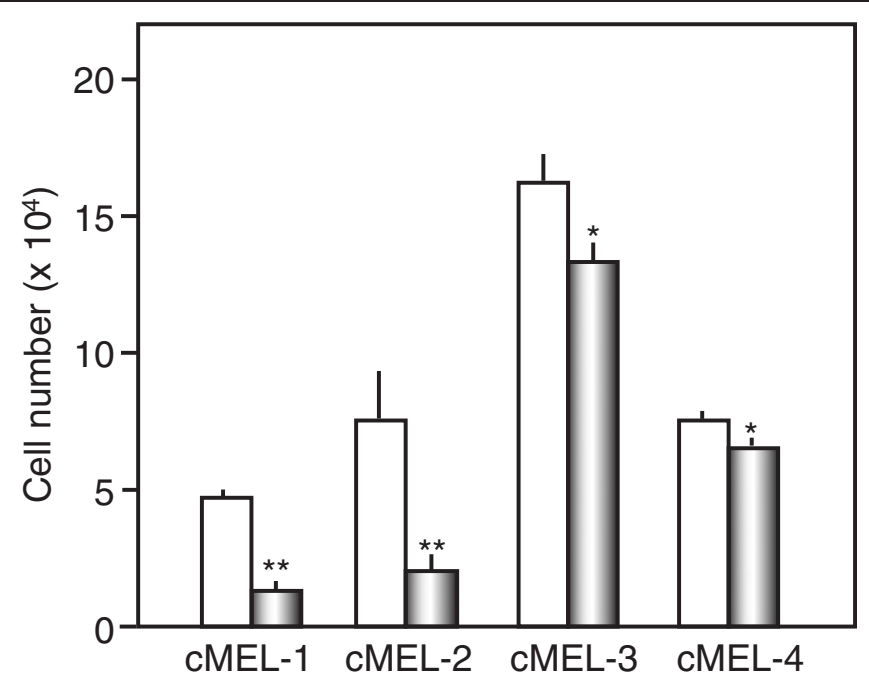

Figure 2 Antiproliferative activity against 4 canine melanoma cells. Canine melanoma cells $\left(1 \times 10^{4}\right.$ cells) were treated without (white bar) or with $10 \mu \mathrm{M}$ lupeol (gray bar) for 4 days, and the viable cell number was subsequently counted by the Trypan blue exclusion method. ${ }^{*} p<0.05$, ** $p<0.01$ vs untreated cells $(n=3)$.
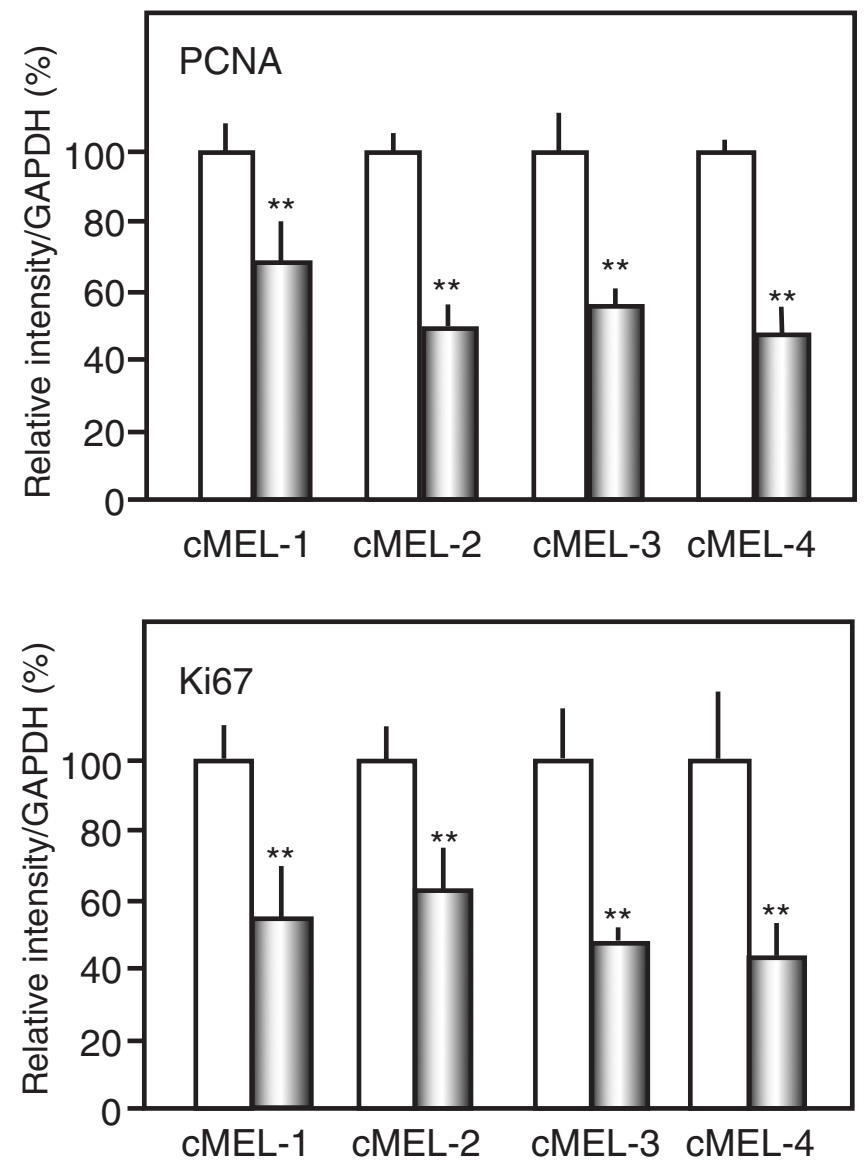

Figure 3 Attenuation of the expression of PCNA and Ki67 genes by lupeol. Four canine melanoma cells $\left(2 \times 10^{5}\right.$ cells) were treated without (white bar) or with lupeol at IC 50 values against each melanoma cell (gray bar) for $48 \mathrm{~h}$, and the gene expression of PCNA and Ki67 was measured by real-time RT-PCR. ${ }^{* *} p<0.01$ vs untreated cells $(n=3)$. 


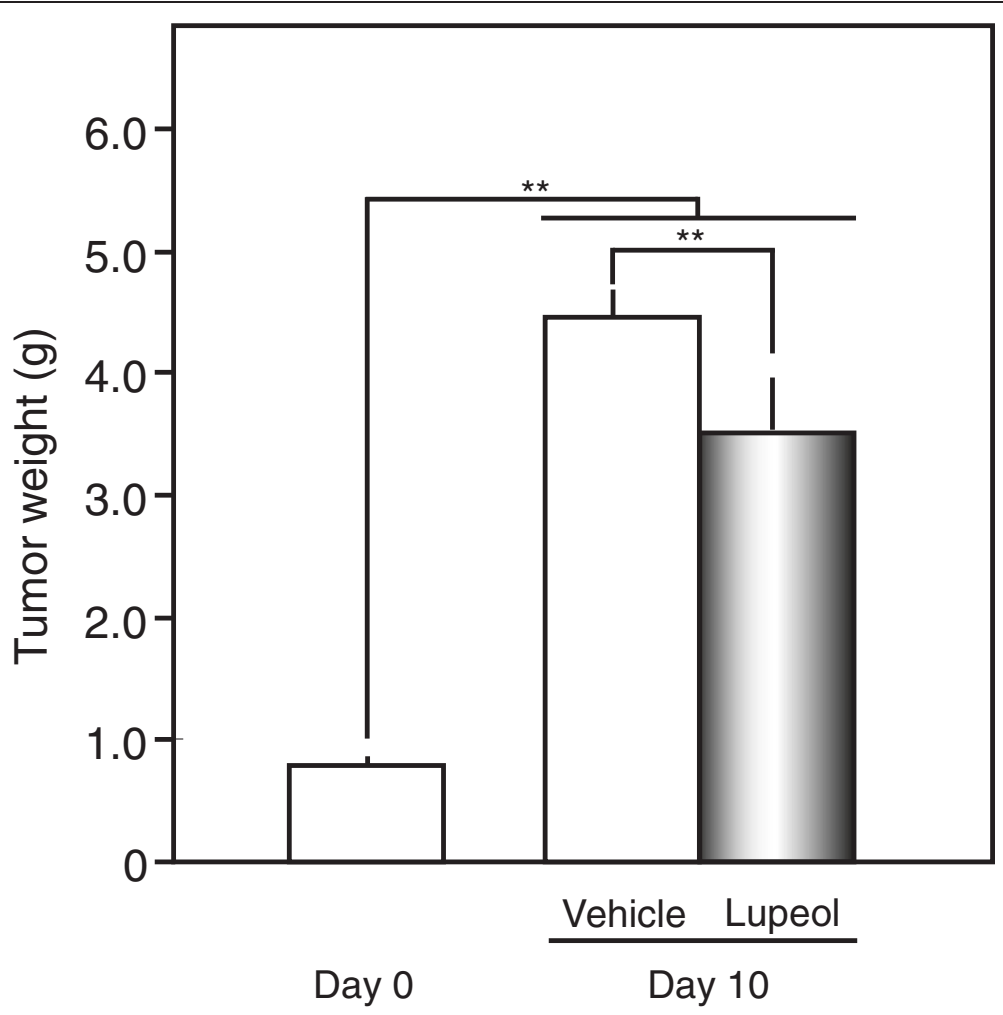

Figure 4 Suppressive effects of the systemic administration of lupeol on tumor growth in melanoma-bearing SCID mice. Single injections of olive oil (vehicle control group; Vehicle) or lupeol (lupeol group; Lupeol) were subcutaneously administered to each mouse on day 0. The weights of tumor tissues were measured 10 days after the injections. ${ }^{* *} p<0.01$ between each group $(n=5)$.

melanoma tissues has been correlated with the presence of malignancy and prognosis (Gould Rothberg et al. 2009). We previously reported that lupeol suppressed the expression of PCNA and Ki67 in B16 mouse melanoma cells both in vitro and vivo. Therefore, we studied the effects of lupeol at each $\mathrm{IC}_{50}$ value against canine melanoma cell growth on the expression of PCNA and Ki67 genes. Realtime RT-PCR analysis revealed that lupeol suppressed the expression of PCNA and Ki67 in 4 canine melanoma cells by $47.4-68.0 \%$ and $43.4-62.5 \%$, respectively (Figure 3 ).

Furthermore, we transplanted cMEL-2 cells into a SCID mouse, and studied the anti-progressive effects of lupeol on tumor tissue (Figure 4). Although the melanoma was 5.7 -fold bigger by day 10 , growth was significantly suppressed by $78.7 \%$ that of the vehicle control with the single administration of lupeol $(p<0.01)$. We administered lupeol to melanoma-bearing mice only once in the present study, and a higher dose and/or repeated injection of lupeol appeared to be more effective in treating the melanoma.

We demonstrated the differentiation-inducing and antiproliferative activities of lupeol on 4 canine melanoma cells both in vitro and in vivo. We intend to establish a nonsurgical treatment for canine melanoma with lupeol based on these results.

\section{Competing interests}

The authors declare that they have no competing interests.

\section{Authors' contributions}

Conceived and designed the experiments: $\mathrm{KO}$ and $\mathrm{KH}$. Analyzed the data: $\mathrm{KO}$ and $\mathrm{KH}$. Agreed with manuscript results and conclusions: $\mathrm{KO}, \mathrm{YN}, \mathrm{YO}$ and $\mathrm{KH}$. Jointly developed the structure and arguments for the paper: $\mathrm{KO}$, $\mathrm{YN}, \mathrm{YO}$ and $\mathrm{KH}$. Made critical revisions to and approved final version: $\mathrm{KH}$. All authors reviewed and approved the final manuscript.

\section{Acknowledgement}

This research was supported in part by the grant program "Enhancement Project of Intellectual Creation Cycle for Akita Prefectural Research Institutes".

\section{Author details}

${ }^{1}$ School of Life and Environmental Science, Azabu University, 1-17-71 Fuchinobe, Chuo-ku, Sagamihara, Kanagawa 252-5201, Japan. ${ }^{2}$ Department of Veterinary Clinical Medicine, School of Veterinary Medicine, Faculty of Agriculture, Tottori University, 4-101, Koyama-Minami, Tottori 680-8553, Japan. ${ }^{3}$ Akita Research Institute of Food and Brewing, 4-26 Sanuki, Araya-machi, Akita 010-1623, Japan.

Received: 3 March 2014 Accepted: 20 October 2014 Published: 25 October 2014

\section{References}

Bergman PJ (2007) Canine oral melanoma. Clin Tech Small Anim Pract 22:55-60 Fernández MA, de Las Heras B, García MD, Sáenz MT, Villar A (2001a) New insights into the mechanism of action of the anti-inflammatory triterpene lupeol. J Pharm Pharmacol 53:1533-1539

Fernández A, Alvarez A, García MD, Sáenz MT (2001b) Anti-inflammatory effect of Pimenta racemosa var. ozua and isolation of the triterpene lupeol. Farmaco 56:335-338 
Gould Rothberg BE, Bracken MB, Rimm DL (2009) Tissue biomarkers for prognosis in cutaneous melanoma: a systematic review and meta-analysis. J Natl Cancer Inst 101:452-474

Hall PA, Levision DA, Woods LA (1990) Proliferating cell nuclear antigen (PCNA) immunolocalization in paraffin sections: an index of cell proliferation with evidence of deregulated expression in some neoplasms. J Pathol 162:285-294

Hata K, Mukaiyama T, Tsujimura N, Sato Y, Kosaka Y, Sakamoto K, Hori K (2006) Differentiation-inducing activity of lupane triterpenes on a mouse melanoma cell line. Cytotechnology 52:151-158

Hata K, Hiwatashi K, Itoh M, Suzuki N, Watanabe T, Takahashi J, Sasaki H (2008) Inhibitory effects of lupeol on 3 T3-L1 preadipocyte differentiation. Phytochem Lett 1:191-193

Itoh M, Hiwatashi K, Abe Y, Kimura F, Toshima G, Takahashi J, Sasaki H, Hata K (2009) Lupeol reduces triglyceride and cholesterol synthesis in human hepatoma cells. Phytochem Lett 2:176-178

Malham P, Husain N, Bhalla S, Gupta RK, Husain M (2010) Proliferating cell nuclear antigen, p53 and micro vessel density: grade II vs. Grade III astrocytoma Indian J Pathol Microbiol 53:20-23

Nitta M, Azuma K, Hata K, Takahashi S, Ogiwara K, Tsuka T, Imagawa T, Yokoe I, Osaki T, Minami S, Okamoto Y (2013) Systemic and local injections of lupeol inhibit tumor growth in a melanoma-bearing mouse model. Biomedical Reports 1:641-645

Oliveria S, Dusza S, Berwick M (2001) Issues in the epidemiology of melanoma. Expert Rev Anticancer Ther 1:453-459

Rassnick KM, Ruslander DM, Cotter SM, Al-Sarraf R, Bruyette DS, Gamblin RM, Meleo KA, Moore AS (2001) Use of carboplatin for treatment of dogs with malignant melanoma: 27 cases (1989-2000). J Am Vet Med Assoc 218:1444-1448

Saleem M (2009) Lupeol, a novel anti-inflammatory and anti-cancer dietary triterpenes. Cancer Lett 28(285):109-115

Sasaki H, Kawarasaki S, Sugawara M, Hata K (2008) Effects of lupeol on visceral fat weights and serum lipoprotein profiles in high-fat diet mice. J Clin Biochem Nutr 43(Suppl 1):422-424

Zeng H, Davis CD (2003) Down-regulation of proliferating cell nuclear antigen gene expression occurs during cell cycle arrest induced by human fecal water in colonic HT-29 cells. J Nutr 133:2682-2687

doi:10.1186/2193-1801-3-632

Cite this article as: Ogihara et al:: Differentiation-inducing and anti-

proliferative activities of lupeol on canine melanoma cells. SpringerPlus 2014 3:632.

\section{Submit your manuscript to a SpringerOpen ${ }^{\circ}$ journal and benefit from:}

- Convenient online submission

- Rigorous peer review

- Immediate publication on acceptance

- Open access: articles freely available online

- High visibility within the field

- Retaining the copyright to your article

Submit your next manuscript at $>$ springeropen.com 